\title{
The Role of Endothelial Progenitor Cells in Coronary Artery Disease: Basic Molecular Mechanisms and Its Clinical Potentials
}

\author{
Yudi Her Oktaviono ${ }^{1,2,}$, Suryo Ardi Hutomo ${ }^{1,2}$, Kevin Luke ${ }^{3}$ \\ ${ }^{1}$ Department of Cardiology and Vascular Medicine, Faculty of Medicine, Universitas Airlangga, Jl. Mayjen Prof. Dr. Moestopo No.47, \\ Surabaya, Indonesia \\ ${ }^{2}$ Dr. Soetomo General Academic Hospital, J1. Mayjen Prof. Dr. Moestopo No.6-8, Surabaya, Indonesia \\ ${ }^{3}$ Faculty of Medicine, Universitas Airlangga, J1. Mayjen Prof. Dr. Moestopo No.47, Surabaya, Indonesia \\ *Corresponding author. E-mail: yhoktaviono@yahoo.com
}

Received date: Apr 5, 2021; Revised date: May 27, 2021; Accepted date: May 27, 2021

\section{Abstract}

B ACKGROUND: Coronary artery disease (CAD) remains as the world number one cause of morbidity and mortality. Endothelial progenitor cells (EPCs) are known to be involved in vascular biology. Current review briefly summarizes the basics of EPCs and its clinical use in CAD.

CONTENT: EPCs were firstly isolated in 1997 and involved in neovascularization. Further evidence defined EPCs into two distinguishable groups, namely: myeloid angiogenic cells (MACs) and endothelial colony forming cells (ECFCs). Common cardiovascular drugs, statin, angiotensin-converting enzyme (ACE) inhibitor, and their combinations, showed beneficial effects on EPCs.
Likewise, the incorporation of EPCs upon CAD intervention management had been recently studied. Intramyocardial EPCs implementation and anti-CD34 antibody-coated stents could provide a promising option for refractory symptoms in CAD.

SUMMARY: Association between EPCs and CAD is very dynamic and complex. EPCs could serve as both therapeutic target and agent in CAD patients. Subsequently, a universal definition of EPCs is needed for greater research in the future.

KEYWORDS: atherosclerosis, coronary artery disease, endothelial progenitor cells, neovascularization

Indones Biomed J. 2021; 13(2): 106-13

\section{Introduction}

In the past few decades, coronary artery disease (CAD) ranked as a leading cause of mortality, morbidity, and human suffering in both developed and developing countries. CAD is estimated to affect 126 million individuals and responsible for 9 million deaths globally.(1) Chronic endothelial dysfunction is widely known to develop into atherosclerosis and $\mathrm{CAD}$, therefore the discovery of endothelial progenitor cells (EPCs) provides a promising future for CAD therapy. $(2,3)$

EPCs are generally described as monocytic progenitor cells which initiate angiogenesis. Interestingly,
EPCs behavior is shown to be associated with CAD pathophysiology, risk factors, and some cardiovascular drugs. Moreover, recent development and implementation of EPCs in CAD management endorse its clinical potency. Current review will summarize the basics of EPCs in CAD and its clinical potency.

\section{Basic of EPCs}

EPCs are generally interpreted as monocytic progenitors with the ability to differentiate into endothelial cells and contribute to new blood vessel development.(3) The first discovery of EPCs is believed in 1932 after capillary-like 
formations encountered in the culture of leukocytes.(4) Fastforward to 1997, the first EPCs were isolated from peripheral human blood.(2) The research beautifully demonstrated that cells which express cluster of differentiation 34 (CD34+) and vascular endothelial growth factor receptor-2 (VEGFR-2+) are involved in new blood vessel formation in mouse and rabbit model.

Many nomenclatures had been used to classify the type of EPCs. Most of them used hematopoietic and non-hematopoietic (5), early- and late-outgrowth (3), or circulating angiogenic cells and outgrowth endothelial cells (6). A novel nomenclature for this ambiguity had been proposed as myeloid angiogenic cells (MACs) and endothelial colony forming cells (ECFCs). MACs substitute terms of hematopoietic, early-outgrowth, and circulating angiogenic cells, whereas ECFCs for non-hematopoietic, late-outgrowth, and outgrowth endothelial cells.(7)

Despite many nomenclatures, the different characteristics between those two are evident. MACs shape like a spindle and appear earlier in culture (less than 1 week) with a relatively short lifespan around 3-4 weeks, while ECFCs form cobblestone-like cells, appear around 2-4 weeks in culture with a longer lifespan duration (around 12 weeks).(6,8) Fundamentally, both MACs and ECFCs have angiogenic potential. However, MACs are incapable to differentiate into endothelial cells and indirectly involved during angiogenesis by secreting interleukin 8 (IL-8) and vascular endothelial growth factor (VEGF) in a paracrine fashion.(8) ECFCs, on the other hand, have the capability to differentiate into endothelial cells and directly involved in angiogenesis by forming vascular tubes in vitro or in vivo. $(8,9)$

Identification of MACs and ECFCs merely based on surface markers is challenging. Many evidences showed slight different surface markers regarding those two. (6,8,10-12) A study exploring surface markers among those EPCs showed that CD45 and CD133 were highly expressed in MACs, while VEGFR2, CD31, CD34, and vascular endothelial (VE)-cadherin were highly expressed in ECFCs.(10) Another study showed MACs highly expressed CD45 and CD14 which can be a key surface marker for distinguishing MACs and ECFCs.(12) It seems defining EPCs based on the surface antigen is quite burdensome since surface markers profile of EPCs may change over time during mobilization and maturation processes.(13) Previous study also gracefully showed that surface markers were changing overtime among MACs and ECFCs.(8)
In principle, the mechanisms of EPCs in neovascularization involve mobilization, homing, and differentiation into endothelial cells.(11,14-16) During ischemia or vascular injury, VEGF and stromal cellderived factor 1 (SDF-1) are upregulated and released in circulation. These substances activate endothelial nitric oxide synthase (eNOS) to produce nitric oxide (NO), followed by activation of matrix metalloproteinase- 9 (MMP9). This MMP then cleavages kit ligand from membrane-bound (mKitL) into soluble kit ligand (sKitL) which releases niche EPCs resided in the bone marrow to circulation through c-Kit binding.(15) There are also different recorded substances that facilitate EPCs mobilization, such as granulocyte (macrophage) colonystimulating factor (GM-CSF), IL-8, C-X-C chemokine ligand 2 (CXCL2), erythropoietin, inflammatory cytokines, or drug (statins). $(17,18)$

After being released into circulation, EPCs target and migrate to their respective location or "homing". The EPCs homing mechanism consists of multistep sequences such as chemoattraction, adhesion, and transmigration. SDF-1 is considered as the most potent chemoattractant which is initially released by aggregated platelets and maintained by smooth muscle cells for days to weeks. Released SDF1 forms a concentration gradient that navigates EPCs to a specific site through CXC receptor (CXCR4) on EPCs. During this process, SDF-1 also stimulates EPCs to express P-selectin glycoprotein ligand-1 (PSGL-1) and bind with the P-selectin on platelets. $(14,15)$

Along with PSGL-1, the adjuvant structure also fortifies EPCs adhesion. MACs express $\beta 1$ - and $\beta 2$ integrins, while ECFCs do not express $\beta 2$-integrins. E-selectin may be related to these cells. These structures also mediate cell to cell interaction and EPCs transmigration to the respective location. $(15,16)$ In addition, other types of integrin, $\alpha v \beta 3$ - and $\alpha v \beta 5$-integrin, appear to be involved in reendothelialization of denuded artery. The final step of homing is tissue invasion which still under investigation, yet it is hypothesized that cathepsins or MMP may be associated with this process.(14)

The EPCs then play their role, which MACs indirectly aid angiogenesis by paracrine mechanism, while ECFCs are directly involved by differentiating into endothelial cells. The role of VEGF and NO are crucial for the differentiation process, yet the process is largely unknown. $(14,16)$ It is worth mentioning, there are still many unsolved questions regarding EPCs and its mechanism in vascular biology, thus further research of EPCs is necessary. 
EPCs in CAD and

Its Related Risk Factors

Despite limited information regarding EPCs, their involvement in vascular biology is evident. EPCs in CAD patients are not merely reduced in number, yet also become dysfunctional. An early study demonstrated that EPCs were $40 \%$ lower compared to healthy control. Moreover, impairment of its migratory response was also associated with CAD risk factors.(19) Number of EPCs are also related with $\mathrm{CAD}$ vessel involvement in which for every increase of 10 colony forming units (CFUs), multivessel CAD lowered by 20\%.(20) This phenomenon may be caused by the inhibitory effect of oxidized LDL (oxLDL) on eNOS, thus compromising EPCs adhesive, migratory, tube formation, and survival in a dose-dependent fashion.(21)

Another study revealed a significant aspect of C-X-C chemokine receptor type 7 (CXCR-7) in EPCs function. Impaired ECFCs function of CAD patients appeared to be related with down-regulated CXCR7.(22) In fact, CXCR7 gene transfer to these cells significantly enhances cell adhesion and angiogenesis capacity through extracellular signal-regulated kinase (ERK) phosphorylation and vascular endothelial growth factor A (VEGFA) expression. Hence, the CXCR7/phosphorylated-ERK signaling pathway seems crucially implicated EPCs function in CAD patients. Attractively, a recent study demonstrated non-pharmacological intervention, namely shear stress, actually improves CXCR7 regulation together with EPCs proliferation, adhesion, and migration abilities.(23) However, the clear mechanism of how shear stress affects CXCR7 is yet to be elucidated.

During ischemic conditions, an acidic environment is developed. Low $\mathrm{pH}$ has inconclusive effects on EPCs. One study suggested an acidic environment inhibits EPCs function (24), while other evidence showed acidic preconditioning for EPCs is greatly increased survival and angiogenic ability under ischemic conditions (25). Despite these contrary results, the latest study prevailed role of G-protein-coupled receptor 4 (GPR4) as pH sensors and necessary for EPCs acid conditioning in CAD patients.(26) During the acidic condition, GPR4 is activated and induced signaling pathway involving by phosphorylating signal transducer and activator of transcription 3 (STAT3) and subsequent VEGFA expression, which boosts angiogenesis. Unfortunately, GPR4 expression is down-regulated in CAD patients, compromising EPCs function.
One interesting fact is that during acute conditions such as acute myocardial infarction (AMI), the number of EPCs increases. One systematic review demonstrated an increased number of EPCs (CD34+ or CFU-ECs) in patients with AMI and unstable angina compared to stable angina and healthy control.(27) One study had beautifully demonstrated EPCs traffic in AMI patients. CD34+ cells were increased to 5.8-fold in AMI patients within median duration of 195 minutes. This rapid mobilization peaked early after onset, decreased after 7 days, and normalized within 2 months. Higher plasma levels of SDF-1 and VEGF were also recorded, confirming their role as EPCs mobilizers. Additionally, previous evidence in AMI animal model exhibited EPCs cardioprotective feature through VEGF/VEGFR-2/p-Akt cascade, hence ameliorating eNOS function.(28)

Influence of cardiovascular risk factors on EPCs is still controversial. One systematic review consists of small study samples demonstrated that smoking, hypertension, diabetes mellitus type-1 or type-2, dyslipidemia, and aging were related to low number of EPCs.(27) Likewise, a study in metabolic syndrome population without diabetes and cardiovascular diseases revealed a significant reduction of EPCs number and function.(29) Negative effect of cardiovascular risk factors toward EPCs generally speculated by disruption of NO production. Diabetes mellitus and dyslipidemia lowers eNOS alteration via phosphatidylinositol-3 (PI-3) kinase/ protein kinase $\mathrm{B}(\mathrm{PKB}) / \mathrm{Akt} / \mathrm{eNOS} /$ nitric oxide signaling cascade.(30) Smoking induces oxidative stress and disrupts EPCs function possibly by methylation process and eNOS reduction.(31) Hypertension and aging are associated with decreased NO synthesis and increased oxidative species. (32) Besides, low growth hormone and insulin growth factor-1 during aging is also a possible mechanism in EPCs impairment.(33) Contrary to these findings, one study with 571 participants showed that there was a weak association between the number of EPCs and certain cardiovascular risk factors, yet a strong positive association with Framingham score which speculated as a protective mechanism available.(34) Further researches are needed to elucidate this difference.

\section{EPCs as Therapeutic Targets of CAD Management}

Studies had demonstrated that reduced EPCs is related to CAD severity, such as vessel involvement, disease progression, and SYNTAX score.(20,35,36) This reduced 
EPCs may dampen vascular repair function, disrupting vascular injury-repair biology.(37) Therefore, EPCs could be considered as a promising therapeutic target in CAD management.

Marvelously, some cardiovascular drugs are proved to improved EPCs number and functions. Statins, a hydroxymethylglutaryl-coenzyme A (HMG-CoA) inhibitors, are well-documented for its pleiotropic effects in improving EPCs number, migration, and proliferation in CAD patients.(38-41) An in vivo study also demonstrated EPCs differentiation on statin treatment. This effect may be explained by PI-3 kinase/Akt cascade regulation by statins since inhibition of this cascade diminished EPCs improvement.(42)

Clinically speaking, high-intensity statins demonstrated more favorable effects in EPCs. Previous studies demonstrated that atorvastatin and rosuvastatin significantly improved EPCs migration compared to simvastatin. $(40,43)$ On top of that, atorvastatin also demonstrated the highest enhancement in EPCs proliferation.(41) This evidence endorsed study in human which using pre-treatment atorvastatin before performing percutaneous coronary intervention (PCI). Administering $80 \mathrm{mg}$ atorvastatin for 3 days before PCI in naïve CAD patient exhibited a 3.5 fold-increase in EPCs and persisted for 24-hour.(44)

A later study, HIPOCRATES Study, compared EPCs in patients receiving high- and low-dose statin therapy before PCI.(45) The high dose group received the first dose of $80 \mathrm{mg}$ atorvastatin 18-24 hours before, the second dose of $40 \mathrm{mg}$ 2-4 hours before, and a long-term dose of $20 \mathrm{mg}$ after PCI procedure, while the low dose group only received $20 \mathrm{mg}$ of simvastatin. The high dose group showed significant higher CFUs levels before PCI, yet no difference after 24-hour post PCI compared to the low dose group. It is hypothesized that high levels of CFUs EPCs due to high dose statin provides a protective endothelial mechanism and reached the plateau phase, hence less prominent EPCs surge was observed.

Besides statins, ACE inhibitors are also known to have a pleiotropic effect on EPCs. This condition is probably mediated through bradykinin B2-receptor cascade and upregulation of eNOS.(46) CAD patients who received 5 mg of ramipril each day for 4 weeks manifested an increase of 1.5-fold and 2.5-fold EPCs by week-1 and -4, respectively.(47) Furthermore, its proliferation, migration, adhesion, and tube-forming capacity were also markedly improved along with increased NO and decreased systolic blood pressure.
Another study compared enalapril $20 \mathrm{mg}$ with zofenopril $30 \mathrm{mg}$ in newly diagnosed hypertensive patients for 5 years follow-up.(48) This study demonstrated similar increase of EPCs between groups and marked inverse correlation between EPCs number and carotid intima media thickness. A recent study tested various types of ACE inhibitors and observed interesting findings. Captopril, ramipril, and lisinopril were proved to enhance EPCs migration in a dose-dependent fashion.(49) At the given dose, $1 \mathrm{mM}$ and $10 \mathrm{mM}$, captopril outperformed other ACE inhibitors. However, for $100 \mathrm{mM}$ dose, lisinopril took the lead.

The latest evidence also endorsed secretomes influence on EPCs. In a recent study conducted by the authors, administration of human umbilical cord blood mesenchymal stem cells derived secretome was found to significantly improve the function (proliferation and migration) of EPC derived from CAD patients.(50) This effect was synergistic with the concomitant administration of statins and also ACE inhibitors. Despite the lack of exact mechanisms and compositions of secretomes that are still under-investigated, these findings could become the basis for the use of secretomes as a new modality for CAD therapy.

\section{EPCs in CAD Therapeutics}

In stable $\mathrm{CAD}$, the number and function of circulating CD34(+) CD133(+) progenitor cells decreased with age, whereas those mobilized and circulating in AMI did not. (51) Although vast advancements in CAD treatment, in some cases, symptoms may persist even with optimal intervention. This condition is referred as refractory angina (RA) or ischemic cardiomyopathy (ICM).(52,53) Growing evidence supports intramyocardial autologous CD34+ cells implantation for RA.

Previously, two trials had been conducted to evaluate CD34+ cells intramyocardial therapy. The initial study, ACT34-CMI Study, enrolled 24 participants and evaluated 3 different doses of CD34+ cells injection: $5 \times 10^{4}, 1 \times 10^{5}$, and $5 \times 10^{5}$ cells $/ \mathrm{kg}$.(54) Marked reduction in angina frequency, severity based on Canadian Cardiovascular Society (CCS) class, and nitroglycerine usage were documented. Additionally, slight improvements were also observed in exercise tolerance and perfusion imaging by singlephoton emission computerized tomography (SPECT). Incidence of serious adverse events was also distributed among participants. Another randomized controlled trial 
revealed that coronary artery bypass graft $(\mathrm{CABG})$ using trans-epicardial and trans-septal autologous CD133(+) bone marrow cells implantation improved left-ventricular function in low EF coronary artery disease patients. CD133(+) progenitor cells improve cardiac function and repair the myocardium by stimulating neovascularization and angiogenesis.(55)

Later, phase II ACT34-CMI Study was published in 2011 enrolling a total of 167 "no-option" RA patients. (56) This study evaluated 2 doses, $1 \times 10^{5}$ and $5 \times 10^{5}$ cells/ $\mathrm{kg}$, for 12 months. Interestingly, low-dose CD34+ therapy outperformed other groups. Weekly angina frequency, exercise tolerance, and SPECT imaging results were significantly improved compared to control and highdose group during 6 months and 12 months follow-up. Improvement was also observed in CCS class reduction and nitroglycerine usage. Major adverse cardiac events (MACEs) were not different among groups, yet no deaths were observed in the treated group compared to control group (5.4\%).

Further observation in 24 months also revealed a significant reduction in angina frequency in both low- and high-dose compared to control group.(57) MACEs rate was significantly reduced in treated groups $(21.8 \%$ for lowand $16.2 \%$ for high-dose) compared to control (33.9\%). Specifically, mortality rate was also lower in the treated group (1.8\% for low- and $3.6 \%$ for high dose) compared to control (12.5\%). Recently, a trial design for phase III had been planned.(58)

A different trial, RENEW Trial, focused on CD34+ intramyocardial injection towards total exercise time (TET).(59) This trial compared 3 following groups: the treatment group received intramyocardial autologous CD34+ cells dosed from $1 \times 10^{5}$ to $1 \times 10^{7}$ cells $/ \mathrm{kg}$, G-CSF stem cell mobilization, apheresis; active control received the same regiment with treatment group except for CD34+ injection; and standard control without any intervention. Unfortunately, the trial was terminated early, hence the results should cautiously be interpreted. Overall, CD34+ showed an improvement in TET, yet was not statistically significant compared to active control. Angina frequency was markedly reduced in the treatment and active control group, yet the relative risk for angina was only significant in 6 months follow-up. $(\mathrm{RR}=0.58, p=0.02)$.

Besides intramyocardial implantation, EPCs had been combined with PCI procedure. During balloon or stent deployment, endothelial lining of the coronary artery is disrupted, leading to neointimal hyperplasia and restenosis.
Therefore, coating stents with anti-CD34 antibodies to capture CD34+ cells seems to be rational since these cells are involved in vascular healing.(60)

The first human study using this stent was HEALING First in Man (FIM) study. HEALING FIM study was a nonrandomized, prospective, single-center study with 16 de novo CAD patients.(61) At 6 months follow-up, most angiographic morphology remains similar to post-PCI, mean late luminal loss was $0.63 \pm 0.52 \mathrm{~mm}$ and $27.2 \pm 20.9 \%$ in-stent restenosis. The MACEs and cerebrovascular events rate were $6.3 \%$, despite only 1 -month dual antiplatelet therapy. This result initiated later studies, such as HEALING II, e-HEALING, and HEALING IIb.(62)

Another trial, the TRI-stent adjudication study (TRIAS), was a randomized, prospective, singlecenter study composed of 193 participants.(62) The study compared EPCs-capture stents (ECS) to paclitaxeleluting stents (PES) in de novo lesions with a high risk of restenosis. At 6 and 12 months of follow-up, PES outperformed ECS with $0.55 \pm 0.61 \mathrm{~mm}$ and $1.14 \pm 0.64$ $\mathrm{mm}$ in in-stent late loss, respectively. Further, PES also demonstrated lower target-vessel failure, even not statistically significant $(10.5 \%$ vs. $17.3 \%, p=0.172)$. However, the result may be underpowered due to study design transformation into an international multicenter study. The TRIAS trial was divided into two classes which compared ECS with drug-eluting stent (DES) in TRIASHR and bare-metal stent (BMS) in TRIAS-LR toward MACEs and clinical target lesion revascularization.(63) Surprisingly, ECS did not provide any difference to DES at 1 and 2 years follow-up. $(64,65)$ Five years follow up of TRIAS-LR also exhibited similar results.(66)

Despite the unsatisfying performance of ECS to DES in terms of target lesion failure, a combination of EPCs capturing technology along with Sirolimus elution had been introduced as COMBO dual-therapy stent. This combination considers reendothelialization aspects of EPCs as well as restenosis prevention of Sirolimus. Recent trials (REMEDEE, REMEDEE-OCT, and Japan-USA HARMONEE) combined DES with anti-CD34 antibody coating and compared it toward DES. Interestingly, the combined stent showed a non-inferiority result toward DES.67 However, as several limitations occurred in those trials, (i.e., relative less complex lesion, $<5 \%$ acute coronary syndromes, and $<12 \%$ multivessel diseases), further studies with better designs are required to confirm those noninferiority results could be applied in more complex patients and coronary artery lesion.(68) 


\section{Conclusion}

Association between EPCs and CAD is very dynamic and complex. EPCs could be served as both therapeutic target and agent in CAD patients. Despite many trials performed, a universal definition of EPCs is needed to boost further research in the future.

\section{Authors Contribution}

YHO and SAH were involved in concepting and planning the research. YHO, SAH and KEV collect the information/ literature. YHO, SAH and KEV drafted the manuscript. YHO, SAH and KEV took parts in giving critical revision of the manuscript.

\section{References}

1. Khan MA, Hashim MJ, Mustafa H, Baniyas MY, Al Suwaidi SKBM, AlKatheeri R, et al. Global epidemiology of ischemic heart disease: results from the global burden of disease study. Cureus. 2020; 12: e9349. doi: 10.7759/cureus.9349.

2. Asahara T, Murohara T, Sullivan A, Silver M, Van Der Zee R, Li $\mathrm{T}$, et al. Isolation of putative progenitor endothelial cells for angiogenesis. Science. 1997; 275: 964-7.

3. Donahue M, Quintavalle C, Chiariello GA, Condorelli G, Briguori C. Endothelial progenitor cells in coronary artery disease. Biol Chem. 2013; 394: 1241-52.

4. Ribatti D. The discovery of endothelial progenitor cells. An historical review. Leuk Res. 2007; 31: 439-44.

5. Asahara T, Kawamoto A, Masuda H. Concise review: circulating endothelial progenitor cells for vascular medicine. Stem Cells. 2011; 29: 1650-5.

6. Chopra H, Hung MK, Kwong DL, Zhang CF, Pow EHN. Insights into endothelial progenitor cells: Origin, classification, potentials, and prospects. Stem Cells Int. 2018; 2018: 9847015. doi: 10.1155/2018/9847015

7. Medina RJ, Barber CL, Sabatier F, Dignat-George F, MeleroMartin JM, Khosrotehrani $\mathrm{K}$, et al. Endothelial progenitors : a consensus statement on nomenclature. Stem Cells Transl Med. 2017; 6: 1316-20.

8. Hur J, Yoon CH, Kim HS, Choi JH, Kang HJ, Hwang KK, et al. Characterization of two types of endothelial progenitor cells and their different contributions to neovasculogenesis. Arterioscler Thromb Vasc Biol. 2004; 24: 288-93.

9. Mukai N, Akahori T, Komaki M, Li Q, Kanayasu-Toyoda T, IshiiWatabe A, et al. A comparison of the tube forming potentials of early and late endothelial progenitor cells. Exp Cell Res. 2008; 314: 430-40.

10. Cheng CC, Chang SJ, Chueh YN, Huang TS, Huang PH, Cheng $\mathrm{SM}$, et al. Distinct angiogenesis roles and surface markers of early and late endothelial progenitor cells revealed by functional group analyses. BMC Genomics. 2013; 14: 182. doi: 10.1186/1471-2164-
14-182.

11. Nova-Lamperti E, Zúñiga F, Ormazábal V, Escudero C, Aguayo C. Vascular regeneration by endothelial progenitor cells in health and diseases. In: Microcirculation Revisited - From Molecules to Clinical Practice. London: InTech; 2016. doi: 10.5772/64529.

12. Sieveking DP, Buckle A, Celermajer DS, Ng MKC. Strikingly different angiogenic properties of endothelial progenitor cell subpopulations: insights from a novel human angiogenesis assay. $\mathrm{J}$ Am Coll Cardiol. 2008; 51: 660-8.

13. Shantsila E, Watson T, Tse HF, Lip GYH. New insights on endothelial progenitor cell subpopulations and their angiogenic properties. J Am Coll Cardiol. 2008; 51: 669-71.

14. Urbich C, Dimmeler S. Endothelial progenitor cells: Characterization and role in vascular biology. Circ Res. 2004; 95: 343-53.

15. Li DW, Liu ZQ, Wei J, Liu Y, Hu L Sen. Contribution of endothelial progenitor cells to neovascularization. Int J Mol Med. 2012; 30: 1000-6.

16. George AL, Bangalore-Prakash P, Rajoria S, Suriano R, Shanmugam A, Mittelman A, et al. Endothelial progenitor cell biology in disease and tissue regeneration. J Hematol Oncol. 2011; 4: 24. doi: 10.1186/1756-8722-4-24

17. Tilling L, Chowienczyk P, Clapp B. Progenitors in motion: Mechanisms of mobilization of endothelial progenitor cells. Br J Clin Pharmacol. 2009; 68: 484-92.

18. Hristov M, Erl W, Weber PC. Endothelial progenitor cells: mobilization, differentiation, and homing. Arterioscler Thromb Vasc Biol. 2003; 23: 1185-9.

19. Vasa M, Fichtlscherer S, Aicher A, Adler K, Urbich C, Martin H, et al. Number and migratory activity of circulating endothelial progenitor cells inversely correlate with risk factors for coronary artery disease. Circ Res. 2001; 89: E1-7. doi: 10.1161/hh1301.093953.

20. Kunz GA, Liang G, Cuculoski F, Gregg D, Vata KC, Shaw LK, et al. Circulating endothelial progenitor cells predict coronary artery disease severity. Am Heart J. 2006; 152: 190-5.

21. Ma FX, Zhou B, Chen Z, Ren Q, Shi HL, Sawamura T, et al. Oxidized low density lipoprotein impairs endothelial progenitor cells by regulation of endothelial nitric oxide synthase. J Lipid Res. 2006; 47: 1227-37.

22. Cao Z, Tong X, Xia W, Chen L, Zhang X, Yu B, et al. CXCR7/p-ERKSignaling is a novel target for therapeutic vasculogenesis in patients with coronary artery disease. PLoS One. 2016; 11: e0161255. doi: 10.1371/journal.pone.0161255

23. Zhou H, Tu Q, Zhang Y, Xie HQ, Shuai QY, Huang XC, et al. Shear stress improves the endothelial progenitor cell function via the CXCR7/ERK pathway axis in the coronary artery disease cases. BMC Cardiovasc Disord. 2020; 20: 403. doi: 10.1186/s12872-02001681-0.

24. Huang S, He P, Xu D, Li J, Peng X, Tang Y. Acidic stress induces apoptosis and inhibits angiogenesis in human bone marrow-derived endothelial progenitor cells. Oncol Lett. 2017; 14: 5695-702.

25. Mena HA, Zubiry PR, Dizier B, Schattner M, Boisson-Vidal C, Negrotto S. Acidic preconditioning of endothelial colony-forming cells (ECFC) promote vasculogenesis under proinflammatory and high glucose conditions in vitro and in vivo. Stem Cell Res Ther. 2018; 9: 120. doi: 10.1186/s13287-018-0872-7.

26. Ouyang S, Li Y, Wu X, Wang Y, Liu F, Zhang J, et al. GPR4 signaling is essential for the promotion of acid-mediated angiogenic capacity of endothelial progenitor cells by activating STAT3/VEGFA pathway in patients with coronary artery disease. Stem Cell Res Ther. 2021; 12: 149. doi: 10.1186/s13287-021-02221-z.

27. Aragona CO, Imbalzano E, Mamone F, Cairo V, Lo Gullo A, D'Ascola $\mathrm{A}$, et al. Endothelial progenitor cells for diagnosis and prognosis in 
cardiovascular disease. Stem Cells Int. 2016; 2016: 8043792. doi: 10.1155/2016/8043792.

28. Cheng Y, Jiang S, Hu R, Lv L. Potential mechanism for endothelial progenitor cell therapy in acute myocardial infarction: Activation of VEGF- PI3K/AkteNOS pathway. Ann Clin Lab Sci. 2013; 43: 395401.

29. Jialal I, Devaraj S, Singh U, Huet BA. Decreased number and impaired functionality of endothelial progenitor cells in subjects with metabolic syndrome: Implications for increased cardiovascular risk. Atherosclerosis. 2010; 211: 297-302.

30. Huang PH, Chen JW, Lin SJ. Effects of cardiovascular risk factors on endothelial progenitor cell. Acta Cardiol Sin. 2014; 30: 375-81.

31. He Z, Chen Y, Hou C, He W, Chen P. Cigarette smoke extract changes expression of endothelial nitric oxide synthase (eNOS) and p16(INK4a) and is related to endothelial progenitor cell dysfunction. Med Sci Monit. 2017; 23: 3224-31.

32. Higashi Y, Kihara Y, Noma K. Endothelial dysfunction and hypertension in aging. Hypertens Res. 2012; 35: 1039-47.

33. Thum T, Hoeber S, Froese S, Klink I, Stichtenoth DO, Galuppo P, et al. Age-dependent impairment of endothelial progenitor cells is corrected by growth hormone mediated increase of insulin-like growth factor-1. Circ Res. 2007; 100: 434-43.

34. Xiao Q, Kiechi S, Patel S, Oberhollenzer F, Weger S, Mayr A, et al. Endothelial progenitor cells, cardiovascular risk factors, cytokine levels and atherosclerosis - Results from a large populationbased study. PLoS One. 2007; 2: e975. doi: 10.1371/journal. pone.0000975.

35. Briguori C, Testa U, Riccioni R, Colombo A, Petrucci E, Condorelli $\mathrm{G}$, et al. Correlations between progression of coronary artery disease and circulating endothelial progenitor cells. FASEB J. 2010; 24: 1981-8.

36. Chiang $\mathrm{CH}$, Leu HB, Huang PH, Chung FP, Huang CC, Wu TC, et al. SYNTAX Score is associated with circulating endothelial progenitor cells in patients with coronary artery disease. Acta Cardiol Sin. 2012; 28: 216-24.

37. Schmidt-Lucke C, Rössig L, Fichtlscherer S, Vasa M, Britten M, Kämper $\mathrm{U}$, et al. Reduced number of circulating endothelial progenitor cells predicts future cardiovascular events: Proof of concept for the clinical importance of endogenous vascular repair. Circulation. 2005; 111: 2981-7.

38. Chiang KH, Cheng WL, Shih CM, Lin YW, Tsao NW, Kao $\mathrm{YT}$, et al. Statins, HMG-CoA reductase inhibitors, improve neovascularization by increasing the expression density of CXCR4 in endothelial progenitor cells. PLoS One. 2015; 10: e0136405. doi: 10.1371/journal.pone.0136405.

39. Vasa M, Fichtlscherer S, Adler K, Aicher A, Martin H, Zeiher AM, et al. Increase in circulating endothelial progenitor cells by statin therapy in patients with stable coronary artery disease. Circulation. 2001; 103: 2885-90.

40. Savitri TR, Oktaviono YH, Soemantri D. Effect of statins on endothelial progenitor cell (EPC) migration from peripheral blood of stable coronary artery disease patient. Indones J Cardiol. 2019; 40: 202-5.

41. Meuthia F, Oktaviono YH, Soemantri D. Effects of statins on endothelial progenitor cell proliferation from peripheral blood of stable coronary artery disease patient. Indones J Cardiol. 2017; 38: 6-12.

42. Dimmeler S, Aicher A, Vasa M, Mildner-rihm C, Adler K, Tiemann $\mathrm{M}$, et al. increase endothelial progenitor cells via the PI 3-kinase / Akt pathway. 2001; 108: 365-6.

43. Oktaviono YH, Farabi MJ Al, Meuthia F, Savitri TVR, Soemantri D. Rosuvastatin is superior compared to simvastatin and atorvastatin to induce endothelial progenitor cells migration. J Clin Diagnostic Res. 2019; 1077: 5-8.

44. Hibbert B, Ma X, Pourdjabbar A, Simard T, Rayner K, Sun J, et al. Pre-procedural atorvastatin mobilizes endothelial progenitor cells: clues to the salutary effects of statins on healing of stented human arteries. PLoS One. 2011; 6: e16413. doi: 10.1371/journal. pone.0016413.

45. Eisen A, Leshem-Lev D, Yavin H, Orvin K, Mager A, Rechavia E, et $a l$. Effect of high dose statin pretreatment on endothelial progenitor cells after percutaneous coronary intervention (HIPOCRATES Study). Cardiovasc Drugs Ther. 2015; 29: 129-35.

46. Silvestre JS, Bergaya S, Tamarat R, Duriez M, Boulanger CM, Levy BI. Proangiogenic effect of angiotensin-converting enzyme inhibition is mediated by the bradykinin B2 receptor pathway. Circ Res. 2001; 89: 678-83.

47. Min TQ, Zhu CJ, Xiang WX, Hui ZJ, Peng SY. Improvement in endothelial progenitor cells from peripheral blood by ramipril therapy in patients with stable coronary artery disease. Cardiovasc Drugs Ther. 2004; 18: 203-9.

48. Cacciatore F, Bruzzese G, Vitale DF, Liguori A, Nigris F De, Fiorito C, et al. Effects of ACE inhibition on circulating endothelial progenitor cells, vascular damage, and oxidative stress in hypertensive patients. Eur J Clin Pharmacol. 2011; 67: 877-83.

49. Oktaviono YH, Ahmad HA, Al Farabi MJ, Gandi P, Givani CL, Lumeno ISP, et al. Enhancement of EPC migration by high-dose lisinopril is superior compared to captopril and ramipril. F1000Research. 2021; 10: 15. doi: 10.12688/f1000research.26395.1.

50. Oktaviono YH, Hutomo SA, Al-Farabi MJ, Chouw A, Sandra F. Human umbilical cord blood-mesenchymal stem cell-derived secretome in combination with atorvastatin enhances endothelial progenitor cells proliferation and migration. F1000Research. 2020; 9: 537. doi: 10.12688/f1000research.23547.2.

51. Kondo T, Shintani S, Maeda K, Hayashi M, Inden Y, Numaguchi $\mathrm{Y}$, et al. The number and function of circulating CD34+CD133+ progenitor cells decreased in stable coronary artery disease but not in acute myocardial infarction. Heart Asia. 2010; 2: 20-3.

52. Gallone G, Baldetti L, Tzanis G, Gramegna M, Latib A, Colombo A, et al. Refractory angina: from pathophysiology to new therapeutic nonpharmacological technologies. JACC Cardiovasc Interv. 2020; 13: 1-19.

53. Briceno N, Schuster A, Lumley M, Perera D. Ischaemic cardiomyopathy: Pathophysiology, assessment and the role of revascularisation. Heart. 2016; 102: 397-406.

54. Losordo DW, Schatz RA, White CJ, Udelson JE, Veereshwarayya $\mathrm{V}$, Durgin M, et al. Intramyocardial transplantation of autologous CD34+ stem cells for intractable angina: A phase I/IIa double-blind, randomized controlled trial. Circulation. 2007; 115: 3165-72.

55. Soetisna TW, Sukmawan R, Setianto B, Mansyur M, Murni TW, Listiyaningsih $\mathrm{E}$, et al. Combined transepicardial and transseptal implantation of autologous CD 133+ bone marrow cells during bypass grafting improves cardiac function in patients with low ejection fraction. J Card Surg. 2020; 35: 740-6.

56. Losordo DW, Henry TD, Davidson C, Sup Lee J, Costa MA, Bass T, et al. Intramyocardial, autologous CD34+ cell therapy for refractory angina. Circ Res. 2011; 109: 428-36.

57. Henry TD, Schaer GL, Traverse JH, Povsic TJ, Davidson C, Lee JS, et al. Autologous $\mathrm{CD} 34+$ cell therapy for refractory angina: 2-year outcomes from the ACT34-CMI study. Cell Transplant. 2016; 25: 1701-11.

58. Povsic T, Sietsema WK, Wang J, Takagi H, Kotynski C, Losordo DW. Design of a confirmatory pivotal study with intramyocardial GCSFmobilized autologous CD34 cells (CLBS14) for the treatment of an 
orphan-sized population with no-option refractory disabling angina. Cytotherapy. 2020; 22: S64. doi: 10.1016/j.jcyt.2020.03.096.

59. Povsic TJ, Henry TD, Traverse JH, Fortuin FD, Schaer GL, Kereiakes DJ, et al. The RENEW Trial: efficacy and safety of intramyocardial autologous $\mathrm{CD} 34+$ cell administration in patients with refractory angina. JACC Cardiovasc Interv. 2016; 9: 1576-85.

60. Sethi R, Lee CH. Endothelial progenitor cell capture stent: Safety and effectiveness. J Interv Cardiol. 2012; 25: 493-500.

61. Aoki J, Serruys PW, van Beusekom H, Ong AT, McFadden EP, Sianos $\mathrm{G}$, et al. Endothelial progenitor cell capture by stents coated with antibody against CD34: the HEALING-FIM (Healthy Endothelial Accelerated Lining Inhibits Neointimal Growth-First In Man) Registry. J Am Coll Cardiol. 2005; 45: 1574-9. doi: 10.1016/j. jacc.2005.01.048.

62. Klomp M, Beijk MAM, de Winter RJ. GenousTM endothelial progenitor cell-capturing stent system: A novel stent technology. Expert Rev Med Devices. 2009; 6: 365-75.

63. Klomp M, Beijk MAM, Verouden NJW, Tijssen JGP, de Winter RJ. Design and rationale of the TRI-stent Adjudication Study (TRIAS) Program. Am Heart J. 2009; 158: 527-532.e1.

64. Klomp M, Beijk MA, Varma C, Koolen JJ, Teiger E, Richardt G, et al. 1-Year outcome of TRIAS HR (TRI-stent Adjudication StudyHigh Risk of restenosis): A multicenter, randomized trial comparing genous endothelial progenitor cell capturing stents with drugeluting stents. JACC Cardiovasc Interv. 2011; 4: 896-904.

65. Beijk MAM, Klomp M, Van Geloven N, Koch KT, Henriques JPS, Baan J, et al. Two-year follow-up of the genousTM endothelial progenitor cell capturing stent versus the taxus liberte stent in patients with de Novo coronary artery lesions with a high-risk of restenosis: A randomized, single-center, pilot study. Catheter Cardiovasc Interv. 2011; 78: 189-95.

66. Juliea PT, Kerkmeijer LS, Woudstra P, Kalkman D, Klomp M, Varma $\mathrm{C}$, et al. Final 5-year results of the TRIAS-LR: a multi-centre, randomized trial comparing the genous endothelial progenitor cell capturing stent with bare metal stents in patients with low risk for restenosis. Eur Heart J. 2020; 41(Suppl 2): 2545. doi: 10.1093/ehjci/ ehaa946.2545.

67. Yamaji K, Kimura T. COMBO dual-therapy stent: non-inferior to drug-eluting stents or stepping back to bare metal stents? Eur Heart J. 2018; 39: 2469-71.

68. Saito S, Krucoff MW, Nakamura S, Mehran R, Maehara A, Al-Khalidi HR, et al. Japan-United States of America Harmonized Assessment by Randomized Multicentre Study of OrbusNEich's Combo StEnt (Japan-USA HARMONEE) study: primary results of the pivotal registration study of combined endothelial progenitor cell capture and drug-eluting. Eur Heart J. 2018; 39: 2460-8. 